\title{
Morphological Demonstration of the Immune Privilege in the Testis using Adjuvants: Tissue Responses of Male Reproductive Organs in Mice Injected with Bordetella pertussigens
}

\author{
Masahiro Itoh, Xiao Hua Chen, Yoshiki Takeuchi and Takanori MikI \\ Department of Anatomy, Kagawa Medical School, Kagawa, Japan
}

Received August 11, 1995

\begin{abstract}
Summary. The testis, the epididymis and the prostate are immunologically suppressed organs in which allogeneic tissue grafts can survive for a long time. In the present study, morphological features of these three organs after systemic administration of immunopotentiators was investigated in mice to determine whether or not this treatment can affect their immunosuppressive circumstances. The animals were intravenously injected with adjuvants, Bordetella pertussigens, then killed 7-10 days later for histological examination. The results showed that the testicular interstitium was completely free from leukocyte infiltration but that the accessory glands (the prostate, the coagulating gland and the seminal vesicle), the vas deferens, the epididymis and the ductuli efferentes received extravasation of leukocytes into their interstitial tissues. This indicates that the testis is resistant to leukocyte infiltration compared with the epididymis and the prostate.
\end{abstract}

The testis, the epididymis and the prostate are unusually hospitable sites for successful transplantation of allogeneic skin, islet cells, thyroid and parathyroid glands (Whitmore and GiTTES, 1977; HEAD et al., 1983b; HeAd and Billingham, 1985; KaZEEM, 1988). Classic privileged sites such as the brain and anterior chamber of the eye owe their immunosuppressive status primarily to a deficient lymphatic drainage. Indeed, experimental interruption of lymphatic drainage or production of an alymphatic skin pedicle can create an immune privileged site for a long graft survival (BARKER and BILLINGHAM, 1968). In contrast, reports of immune privilege in the testis, the epididymis and the prostate are surprising, because their interstitial tissues are well endowed with abundant lymphatic sinusoids and vessels (HEAD et al., 1983a; NEAVES and BILlingham, 1979; KAZEEM, 1983). Two possibilities have previously been given for immune privilege in these three organs; 1 ) immunosuppressive activities of cells and fluid within the reproductive tracts (STITES and ERICKSON, 1975; HURTENBACH and SHEARER, 1982); 2) failure of the sensitization of hosts with allograft antigens due to anomalous lymph drainage whereby some lymphatic trunks in the reproductive organs bypassed regional lymph nodes and opened directly into the systemic blood circulation (NEAVES and Billingham, 1979; HeAD et al., 1983a). Immune privilege in the three reproductive organs has been so far demonstrated by many studies employing the local transplantation system. In the present study, we investigated their immune privileged status from a point of view that the systemic administration of immunopotentiators might hardly affect their histological appearances. We observed the morphological appearances of male reproductive organs in mice injected with potent adjuvants, Bordetella pertussigens (BP), which induce leukocytosis and inflammatory cell extravasation into various tissues (OCHIAI et al., 1972; LEHRER et al., 1977).

\section{MATERIALS AND METHODS}

A/J mice (male, 8 weeks old) were purchased from SLC, Shizuoka, Japan. Mice $(\mathrm{n}=26)$ were intravenously injected with $250 \mu \mathrm{l}$ solution of BP $\left(2 \times 10^{10}\right.$ dead microorganisms/animal, Wako, Osaka, Japan). Over a period of 7-10 days after the treatments, the 
mice were killed by cervical dislocation. The testes with the ductuli efferentes, the epididymides, the vasa deferentia, the accessory glands (the seminal vesicles, the coagulating glands and the prostates), and the testicular arteries and veins were immediately removed and fixed in Bouin's solution for 5 days. Then, the organ samples were embedded in plastic (Technovit 7100; Kulzer \& Co., Wehrheim, Germany). The whole organs were sectioned completely with a $5 \mu \mathrm{m}$ setting on the microtome, after which the sections were stained with hemaoxylin and eosin. The organ samples from $250 \mu 1$ saline-injected mice $(\mathrm{n}=$ 12) were used as controls.

\section{RESULTS}

Macroscopically, no remarkable signs were found in the male reproductive organs of both control and experimental groups. A marked splenomegaly was noted in the experimental group. Results of the microscopical examination are summarized in Table 1. No inflammatory cell responses were found in the control group. In the experimental group, an extravasation of inflammatory cells was found in the interstitium of the accessory glands (Fig. 1a), the vasa deferentia (Fig. 1b), the epididymides (Fig. 1c) and the ducutuli efferentes (Fig. 1d), with no damage to their tubular structures. Moreover, many inflammatory cells were observed around the testicular arteries and veins (Fig. 1e). The inflammatory cells were mainly composed of lymphocytes and neutrophils (Fig. 2). However, the testicular interstitium was completely free from infiltration with inflammatory cells, like the controls (Fig. 3). As an exception, a focal lymphocytic infiltration in the tunica albuginea just adjacent to the straight tubule and the rete testis was noted in only one of twenty-six BP-treated mice (Fig. 4).

\section{DISCUSSION}

Previous studies had shown that BP-treatment induced systemic leukocytosis with significant pathological changes in the lungs, the thymus, the spleen, the lymph nodes and the adrenal glands in the mouse and the rat (OCHIAI et al., 1972; LEHRER et al., 1977; KUwAJIMA, 1980). Nowadays, BP are ordinally used as adjuvants in many experiments for inducing organspecific autoimmune diseases. Classically, the immunization of mice with syngeneic germ cells emulsified in complete Freund's adjuvant followed by injections with BP is necessary for the induction of germ cell autoimmunity with resultant inflammatory cell responses in the testis, the ductuli efferentes, the epididymis and the vas deferens (SATO et al., 1981). The present study showed that the treatment with $\mathrm{BP}$ alone could induce interstitial inflammation in the ducutuli efferentes, the epididymis, the vas deferens and the accessory glands without the aid of anti-germ cell immune responses. However, the testicular interstitium was protected from the leukocyte infiltration in this treatment. This indicates that, distinct from the epididymis and the prostate, the testis is not vulnerable to nonspecific inflammation induced by adjuvants alone. A determination of inflammatory cell subsets in the reproductive tissues of BP-treated mice is now in progress for comparison with that of germ cell autoimmunity-challenged mice. The reason why only the testis is protected from BP-induced leukocyte extravasation into the male reproductive tissues is still unclear. There is a possibility that a permeability of capillary blood vessels against leukocytes in the testis may contribute to the immuneprivileged status of the organ. Previous studies had demonstrated that both Leydig cells and Sertoli cells have immunosuppressive activities in a limited environment in vitro. Testosterone, a product of Leydig

Table 1. Incidence of leukocyte extravasation into male reproductive tissues

\begin{tabular}{|c|c|c|c|c|c|c|c|c|c|c|}
\hline & \multicolumn{3}{|c|}{ Accessory glands } & \multirow{2}{*}{$\begin{array}{c}\text { Vas } \\
\text { deferens }\end{array}$} & \multicolumn{3}{|c|}{ Epididymis } & \multirow{2}{*}{$\begin{array}{l}\text { Ductuli } \\
\text { efferentes }\end{array}$} & \multirow{2}{*}{ Testis } & \multirow{2}{*}{$\begin{array}{l}\text { Testicular } \\
\text { artery } \\
\text { and vein }\end{array}$} \\
\hline & Prostate & $\begin{array}{l}\text { Coagulat- } \\
\text { ing } \\
\text { gland }\end{array}$ & $\begin{array}{l}\text { Seminal } \\
\text { vesicle }\end{array}$ & & caput & corpus & cauda & & & \\
\hline BP-injected mice & $13 / 26$ & $18 / 26$ & $15 / 26$ & $12 / 26$ & $21 / 26$ & $19 / 26$ & $16 / 26$ & $9 / 26$ & $1 / 26^{*}$ & $18 / 26$ \\
\hline Saline-injected mice & $0 / 12$ & $0 / 12$ & $0 / 12$ & $0 / 12$ & $0 / 12$ & $0 / 12$ & $0 / 12$ & $0 / 12$ & $0 / 12$ & $0 / 12$ \\
\hline
\end{tabular}

Numbers of mice with leukocyte extravasation into each tissue/total numbers of mice examined are shown.

* One of twenty-six mice had a focal infiltration with leukocytes in the tunica albuginea but not in the testicular interstitium. 


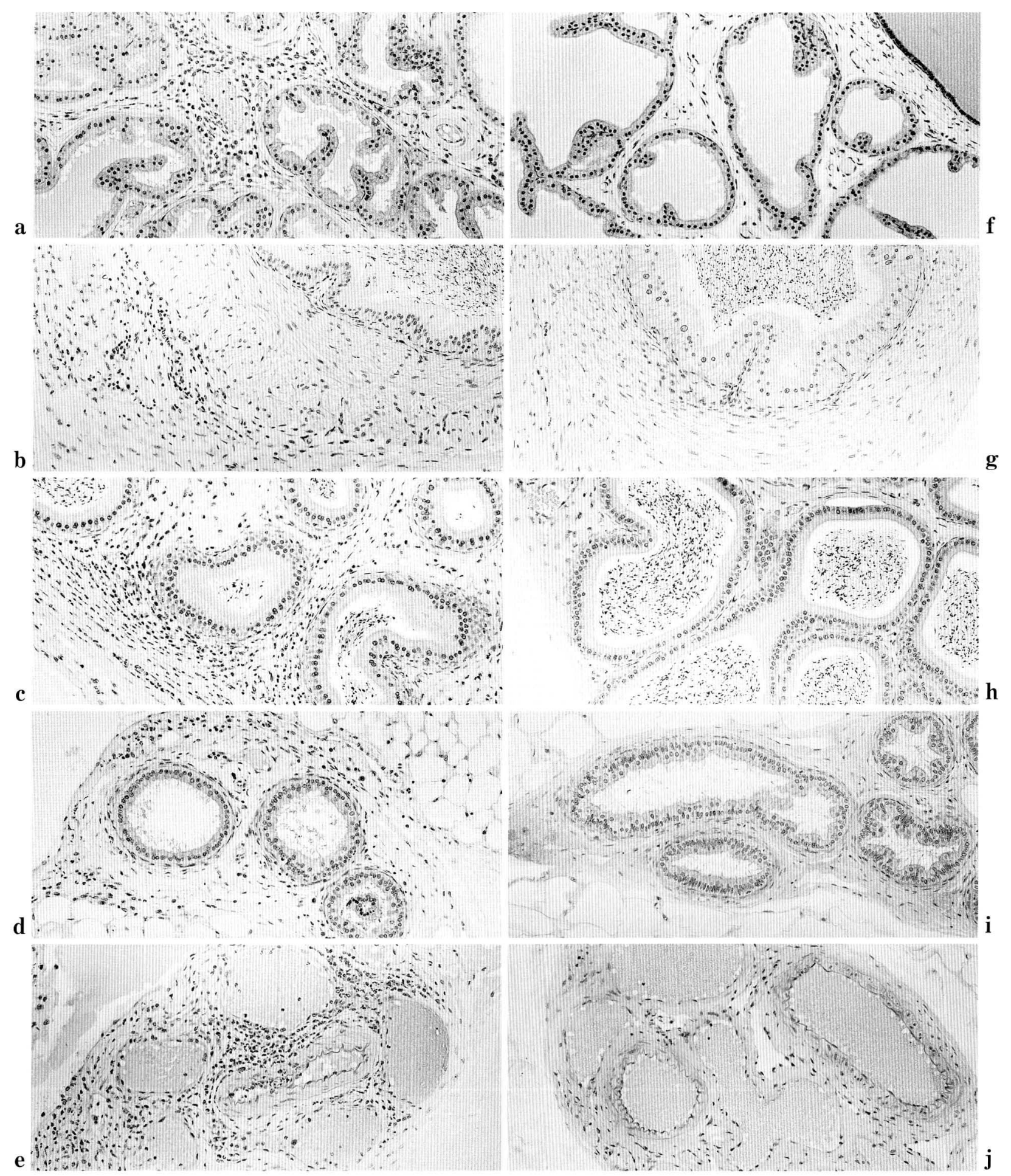

Fig. 1. Sections of the male reproductive organs of BP-injected mice $(\mathbf{a}-\mathbf{e})$ and saline-injected mice $(\mathbf{f}-\mathbf{j})$. The prostates (a and $\mathbf{f}$ ). The vas deferens ( $\mathbf{b}$ and $\mathbf{g})$. The epididymis (c and $\mathbf{h})$. The ductuli efferentes (d and $\mathbf{i})$. The testicular arteries and veins (e and $\mathbf{j}$ ). Many leukocytes have infiltrated into the interstitial tissues of BP-treated mice. $\times 63$ 


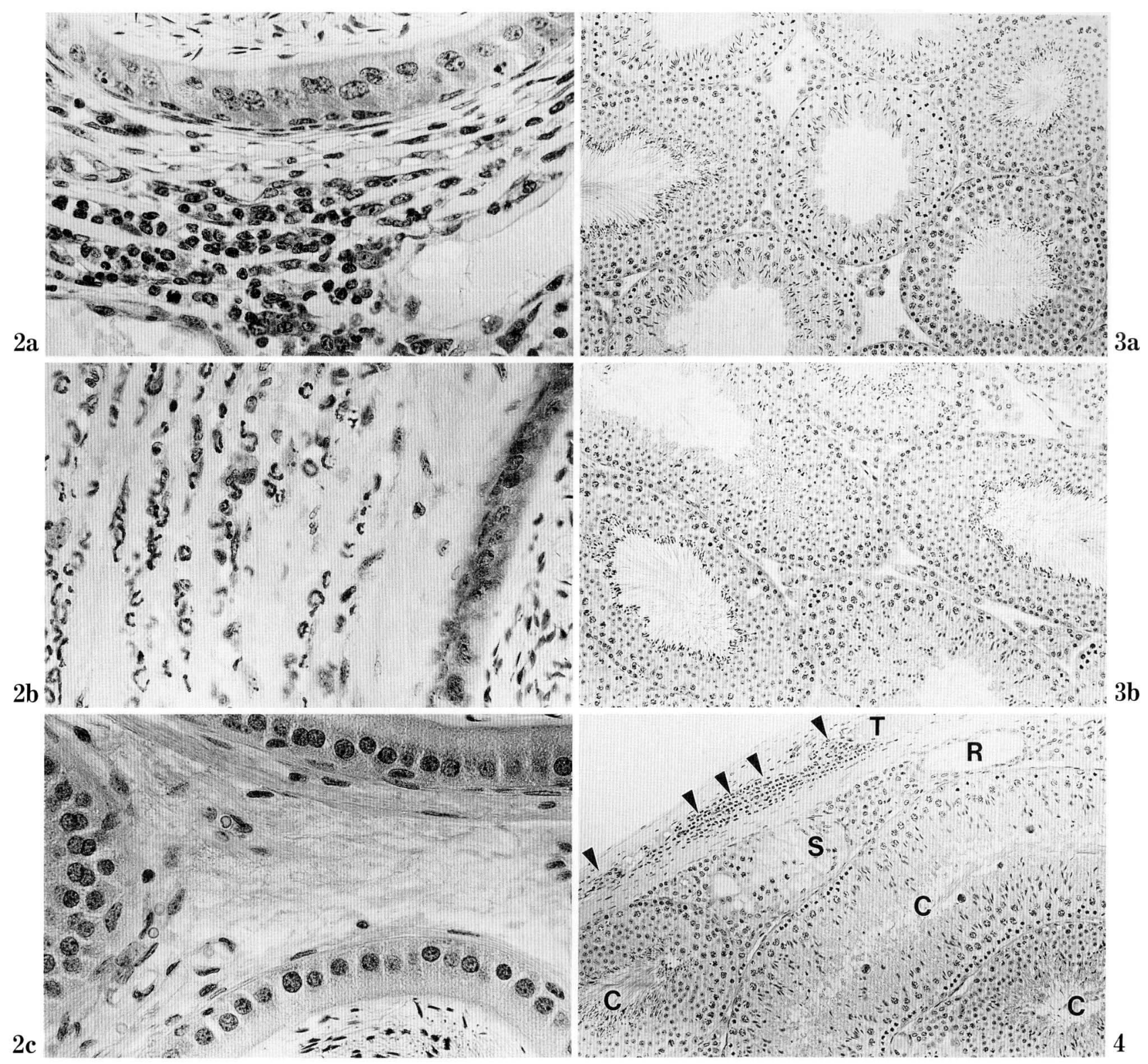

Fig. 2. Epididymal sections of a BP-injected mouse (a and b) and a saline-injected mouse (c). Many lymphocytes (a) and neutrophils ( b) can be observed in the lesions. $\times 145$

Fig. 3. Testicular sections of a BP-injected mouse (a) and a saline-injected mouse (b). No apparent infiltration with leukocytes is noted in either section. $\times 63$

Fig. 4. A testis lesion found in one of twenty-six mice injected with BP. $C$ a convoluted seminiferous tubule, $R$ a rete testis, $S$ a straight tubule, $T$ a tunica albuginea. Arrow heads indicate a leukocytic infiltration. $\times 63$ 
cells, suppresses lymphocyte proliferation (HEAD et al., 1983a, b). Leydig cells spontaneously adhere to lymphocytes and nonspecifically suppress the proliferation of lymphocytes without any dependence on testosterone (BORN and WEKERLE, 1982). Sertoli cells secrete some proteins for the suppression of lymphocyte proliferation (WYATT et al., 1988). These suppressive effects of both Leydig cells and Sertoli cells may be exerted in vivo just after the lymphocytes extravasate into the testicular interstitium. However, considering that not only lymphocytes but also neutrophils did not infiltrate the testicular interstitium in BP-treated mice, capillary vessels in the testis may be resistant to leukocyte extravasation compared to those in other reproductive organs. Before the anti-lymphoproliferative actions by both Leydig cells and Sertoli cells, testicular capillary vessels might first function as an immunosuppressive barrier to protect the testis from inflammatory cell responses.

Acknowledgement. The authors thank Mrs. M. MrYawA. $\mathrm{KI}$ and Mr. W. NAGATA for their technical and secretarial support.

\section{REFERENCES}

Barker, C. F. and R. E. Billingham: The role of afferent lymphatics in the rejection of skin homografts. J. Exp. Med 128: 197-221 (1968).

BORN, W. and H. WEKERLE: Leydig cells nonspecifically suppress lymphoproliferation in vitro: Implications for the testis as an immunologically privileged site. Amer. J. Reprod. Immunol. 2: 291-295 (1982).

HEAD, J. R. and R. E. Billingham: Immune privilege in the testis. II. Evaluation of potential local factors. Transplantation 40: 269-275 (1985).

Head, J. R., W. B. Neaves and R. E. Billingham: Reconsideration of the lymphatic drainage of the rat testis. Transplantation 35: 91-95 (1983a).

- Immune privilege in the testis. I. Basic parameters of allograft survival. Transplantation 36: 423-431 (1983b).

Hurtenbach, U. and G. M. Shearer: Germ cell-induced immune suppression in mice. J. Exp. Med. 155: 17191729 (1982).

KazeEm, A. A.: The assessment of epididymal lymphatics within the concept of immunologically privileged sites. Lymphology 16: 168-171 (1983).
KAzEem, A. A.: A critical consideration of the rat epididymis as an immunologically privileged site. Scand. J. Immunol. 27: 149-156 (1988).

KuwaJima, Y.: Morphological alteration of the adrenal gland following administration of histamine-sensitizing-factor of Bordetella pertussis. Osaka City Med. J. 26: 61-66 (1980).

Lehrer, S. B., R. M. Nakamura and E. M. Tan: Histopathological changes in mice treated with extracts of the histamine-sensitizing factor of Bordetella pertussis. Int. Arch. Allergy Appl. Immunol. 54: 129-142 (1977).

Neaves, W. B. and R. E. Billingham: The lymphatic drainage of the rat prostate and its status as an immunologically privileged site. Transplantation 27 : 127132 (1979).

Ochial, T., K. OKumura, T. TAda and S. Iwasa: Effect of lymphocytosis-promoting factor of Bordetella pertussis on the immune response. I. Suppression of cellular hypersensitivity reactions. Int. Arch. Allergy Appl. Immunol. 43: 196-206 (1972).

Sato, K., K. Hirokawa and S. Hatakeyama: Experimental allergic orchitis in mice. Histopathological and immunological studies. Virchows Arch. Pathol. Anat. 392: 147-158 (1981).

Stites, D. P. and R. P. Erickson : Supppressive effect of seminal plasma on lymphocyte activation. Nature 253: 727-729 (1975).

Whitmore, W. F. and R. F. Gittes: Studies on the prostate and testis as immunologically privileged sites. Cancer Treatment Rep. 61: 217-222 (1977).

Wyatt, C. R., L. Law, J. A. Magnuson, M. D. Griswold and N. S. Magnuson: Suppression of lymphocyte proliferation by proteins secreted by cultured Sertoli cells. J. Reprod. Immunol. 14: 27-40 (1988).

Dr. Masahiro Iтон, M.D.

Department of Anatomy

Kagawa Medical School

Ikenobe, Miki-cho

Kagawa, 761-07 Japan

伊藤 正裕

761-07 香川県木田郡三木町池戸

香川医科大学

解剖学講座第一解剖学 